\title{
Microbial community changes in methanogenic granules during the transition from mesophilic to thermophilic conditions
}

Zhu, Xinyu; Kougias, Panagiotis; Treu, Laura; Campanaro, Stefano; Angelidaki, Irini

Published in:

Applied Microbiology and Biotechnology

Link to article, DOI:

10.1007/s00253-016-8028-0

Publication date:

2017

Document Version

Peer reviewed version

Link back to DTU Orbit

Citation (APA):

Zhu, X., Kougias, P., Treu, L., Campanaro, S., \& Angelidaki, I. (2017). Microbial community changes in methanogenic granules during the transition from mesophilic to thermophilic conditions. Applied Microbiology and Biotechnology, 101(3), 1313-1322. https://doi.org/10.1007/s00253-016-8028-0

\section{General rights}

Copyright and moral rights for the publications made accessible in the public portal are retained by the authors and/or other copyright owners and it is a condition of accessing publications that users recognise and abide by the legal requirements associated with these rights.

- Users may download and print one copy of any publication from the public portal for the purpose of private study or research.

- You may not further distribute the material or use it for any profit-making activity or commercial gain

- You may freely distribute the URL identifying the publication in the public portal 


\section{Microbial community changes in methanogenic granules during the transition from mesophilic to thermophilic conditions}

Xinyu Zhu ${ }^{\mathrm{a}}$, Panagiotis G. Kougias ${ }^{\mathrm{a} *}$, Laura Treu $^{\mathrm{ab}}$, Stefano Campanaro ${ }^{\mathrm{c}}$ and Irini Angelidaki ${ }^{\mathrm{a}}$

${ }^{a}$ Department of Environmental Engineering, Technical University of Denmark, Kgs. Lyngby, DK-2800, Denmark

${ }^{\mathrm{b}}$ Department of Agronomy, Food, Natural resources, Animal and Environment (DAFNAE), viale dell’Università, 16, 35020 Legnaro (Padova), Italy

'Department of Biology, University of Padova, Via U. Bassi 58/b, 35121, Padova Italy

${ }^{*}$ Corresponding author and address:

Panagiotis G. Kougias

Department of Environmental Engineering, Technical University of Denmark

Bld 113, 2800 Lyngby

Denmark

E-mail address: panak@env.dtu.dk, Tel.: +45 4525 1454; fax: +45 45932850 


\begin{abstract}
Upflow anaerobic sludge blanket (UASB) reactor is one of the most applied technologies for various high strength wastewater treatments. The present study analysed the microbial community changes in UASB granules during the transition from mesophilic to thermophilic conditions. Dynamicity of microbial community in granules was analysed using high-throughput sequencing of 16S rRNA gene amplicons and the results showed that the temperature strictly determines the diversity of the microbial consortium. It was demonstrated that most of the microbes which were present in the initial mesophilic community were not found in the granules after the transition to thermophilic conditions. More specifically, only members from family Anaerolinaceae managed to tolerate the temperature change and contributed in maintaining the physical integrity of granular structure. On contrary, new hydrolytic and fermentative bacteria were quickly replacing the old members in the community. A direct result from this abrupt change in the microbial diversity was the accumulation of volatile fatty acids and the concomitant $\mathrm{pH}$ drop in the reactor inhibiting the overall anaerobic digestion process. Nevertheless, by maintaining deliberately the $\mathrm{pH}$ levels at values higher than 6.5, a methanogen belonging to Methanoculleus genus emerged in the community enhancing the methane production.
\end{abstract}

\title{
Keywords
}

UASB; temperature; microbial community; granule structure; 16S rRNA gene

\section{Introduction}

Upflow anaerobic sludge blanket (UASB) reactors are widely used to treat wastewater and produce sustainable energy under different operational conditions. This reactor technology has a lot of advantages such as compactness, low operational cost, low sludge production, and high methane production rate (Zhang et al. 2015). The efficiency of the UASB technology was evaluated by using various feedstocks such as cheese whey (Carrillo-Reyes et al. 2014), palm oil mill effluent (Khemkhao et al. 2012) and starch wastewater (Lu et al. 2015). Potato juice is the thin liquid by-product formed during the production of potato starch after acid-thermal coagulation of proteins (Fang et al. 2011; Bzducha-Wróbel et al. 2015). Since this waste contains high amount of 
biodegradable components it is a suitable feedstock for biogas production. Indeed, a previous study reported that the biochemical methane potential of potato juice was 470

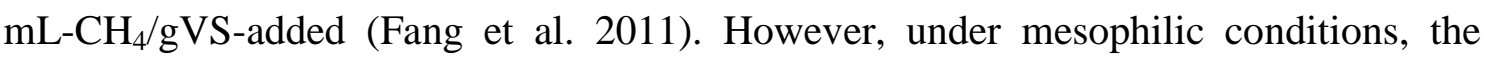

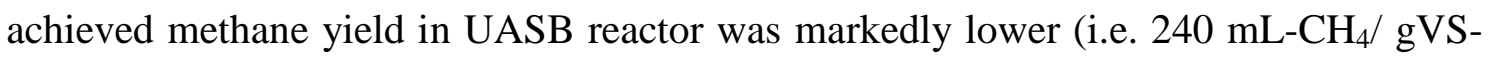
added) and the reactor collapsed at OLR higher than $5.1 \mathrm{~g} \mathrm{COD/(L-reactor)} \mathrm{(Fang} \mathrm{et} \mathrm{al.}$ 2011).

It is well known that temperature is an essential parameter for biological reactions such as the ones occurring during the anaerobic digestion process. Previous studies showed that both substrate degradation and methanogenic activity can be performed with a higher reaction rate at thermophilic conditions (Bouallagui et al. 2004; Boušková et al. 2005). Thermophilically operated UASB reactors were performing well, with similar COD removal and higher methane production rate compared to mesophilic reactors (Castrillon et al. 2002; Parawira et al. 2007). However, UASB reactors are often operating under mesophilic or ambient temperature even though, thermophilic operation typically has a rate-advantage over mesophilic digestion (Mao et al. 2015). Therefore, the availability of active thermophilic granule seeds are extremely limited which makes start-up of UASB reactors at thermophilic temperature difficult. Moreover, the granulation process is very time consuming and typically takes several months depending on many parameters (Vlyssides et al. 2008). One of the strategies to accelerate the start-up of a thermophilic UASB reactor is to use mesophilic granules as inoculum allowing the microbial community to adapt slowly and spontaneously to the new temperature conditions. Several studies reported successful adaptation process by applying stepwise temperature increase and using various types of mesophilic granules; however, it was stated that this procedure cannot always guarantee a stable reactor operation (Fang and Lau 1996; Syutsubo et al. 1997; Khemkhao et al. 2012). A convincing explanation for the operation's failure is still unclear as the microbial dynamics during the temperature transition are far to be elucidated. Khemkhao et al. (2012) employed DGGE analysis to understand the microbial adaptation during a transition from mesophilic to thermophilic conditions in a UASB reactor treating palm oil mill effluent. The result showed a significantly different microbial community transformation from $37{ }^{\circ} \mathrm{C}$ to $57^{\circ} \mathrm{C}$. Nevertheless, the limitations of this molecular technique made it difficult to explore quantitatively and comprehensively the 
community changes.

Recently, the advancement of molecular tools such as the next generation sequencing (NGS) technology allowed a more solid and in depth characterisation of the microbial dynamicity even in complex environmental systems. For example, studies based on 16S rRNA gene amplicons managed to identify a high number of microbial members possessing important roles during the anaerobic digestion process expanding the information deposited in public databases (Kougias et al. 2014; Luo et al. 2015).

In this present study, NGS was applied in order to elucidate the microbial community shifts during the start-up of a thermophilic lab scale UASB reactor inoculated with mesophilic granules. A metagenomic analysis based on 16S rRNA gene sequences was applied at different times along the adaptation process. The results provided insight regarding the changes of microbiota and correlated the shift of microbial consortium to biochemical performance of reactor. This information would be fundamental for the development of time and cost effective strategies for start-up procedures of UASB reactors and process optimisation.

\section{Materials and methods}

\subsection{Characteristics for substrate and inoculate granule}

Raw potato juice used as substrate was obtained from potato-starch processing factory (Karup Kartoffelmelfabrik, Denmark). After arrival to the laboratory the raw potato juice was frozen at $-20^{\circ} \mathrm{C}$ into separate plastic containers. Each container was thawed at $4^{\circ} \mathrm{C}$ before usage and the juice was diluted 7 times with distilled water. The chemical characteristics of the raw potato juice are shown in Table 1. Mesophilic granules used in this study were obtained from a wastewater treatment plant in Netherland (COLSEN) processing potato wastewater as substrate for over 5 years. The granules were stored at $4{ }^{\circ} \mathrm{C}$ and moved at room temperature for 24 hours before use.

\subsection{UASB reactor operation}

The experiment was performed in a lab-scale UASB reactor with working volume of $1.4 \mathrm{~L}$ operating at thermophilic conditions $\left(55^{\circ} \mathrm{C}\right)$. During the start up process, the reactor was inoculated with $600 \mathrm{~mL}$ of mesophilic granules and the rest of the reactor active volume was filled with BA medium (Angelidaki and Sanders 2004). The internal recirculation flow rate of the reactor was $160 \mathrm{~mL} / \mathrm{min}$ corresponding to an upflow 
velocity of $2.2 \mathrm{~m} / \mathrm{h}$. The experiment was divided in three periods, namely a) start up period, b) operation period 1 and c) operation period 2. Granule samples from initial states (G1) as well as the end of each experiment period (G2, G3 and G4) were collected for microbial analyses. The start up period lasted 6 days, during which 40 $\mathrm{mL} /$ day of diluted potato juice were fed to reactor to provide minimum amounts of carbon source and nutrition for microbial growth. In both operation periods, the reactor was fed with diluted potato juice at OLR of 3.97 $\pm 0.19 \mathrm{gVS} /(\mathrm{L}-$-reactor.d) and HRT of 7 days. During the second operation period, the influent feedstock of the reactor was supplemented with $4 \mathrm{~g} \mathrm{NaHCO}_{3} / \mathrm{L}$-reactor to maintain the $\mathrm{pH}$ levels of the reactor at values higher than 6.5. The biogas production was measured daily using an automated displacement gas metering system with $100 \mathrm{~mL}$ cycle (Angelidaki et al. 1992). The pH values, biogas composition and volatile fatty acids (VFA) concentration were measured twice per week.

\subsection{Analytical methods}

Total solids (TS), volatile solids (VS), total COD, total Kjeldahl nitrogen (TKN), and ammonium nitrogen of substrate were measured according to the Standard Methods for the Examination of Water and Wastewater (APHA 2005). Biogas composition was measured using a gas chromatograph (Mikrolab, Aarhus A/S, Denmark), equipped with a thermal conductivity detector (TCD) as previously described (Kougias et al. 2015). VFA and alcohol concentration were measured using a gas chromatograph (Shimadzu GC-2010 AF, Kyoto, Japan), equipped with a flame ionization detector (FID) as described by Kougias et al., (2015). All determinations and measurements were done in triplicate samples.

\subsection{DNA extraction and sequencing}

Triplicate granule samples were taken from the initial mesophilic granules and at the end of each experiment period. Granule samples were washed with BA medium and Genomic DNA was extracted from the sample with PowerSoil ${ }^{\circledR}$ DNA Isolation Kit (MoBio PowerSoil, Carlsbad,CA USA) with extra phenol cleaning steps. During this procedure the supernatant of the first step of extraction (after vortex with beads) was added to $2 \mathrm{ml}$ of phenol: chloroform: isoamylalcohol (25:24:1, v/v, ThermoFisher Scientific), shaken briefly and centrifuged. The resulting supernatant was then processed according to PowerSoil ${ }^{\circledR}$ DNA Isolation protocol. The V4 regions of $16 \mathrm{~S}$ 
ribosomal RNA gene were amplified with PCR using 515f/806r primer (Klindworth, Pruesse et al. 2013). The amplicons were further sequenced by Illumina MiSeq desktop sequencer (Ramaciotti Centre for Genomics, Kensington, Australia).

\subsection{Data analysis}

The raw sequences were processed using CLC Workbench software (V.8.0.2) with Microbial genomics module plug in. A trimming procedure was applied to low quality reads according to default parameters provided by the software and paired sequences were merged. Chimera crossover filter was also applied. Phylogenetic assignment of OTU representative sequences was performed with Multiple Sequence Comparison by Log- Expectation on fixed length trimmed (240 bp) sequences using Greengenes v13_5 database as reference (clustered at 95\%). OTU similarity percent was set at 95\% and the creation of new OTUs was allowed when taxonomy similarity percentage was lower than $80 \%$ with minimum occurrence of five reads. OTUs were aligned using MUSCLE software implemented in CLC software. Maximum Likelihood Phylogeny (tree) was performed with Neighbor Joining as construction method and with Jukes Cantor as nucleotide substitution model to estimate the evolutionary distance between sequences. Bootstrap analysis was performed with 100 replicates to test the certainty of the evolutionary relation and distance. Alpha diversity was measured based on number of OTUs, Chao 1 bias-corrected and Phylogenetic diversity. Beta Diversity (PCoA) was calculated using Bray-Curtis matrix. Predictive functional profiling of OTUs identified at genus level was performed with a specific perl script as previously described (De Francisci et al., 2015). Statistical analyses to identify significance of changes in relative abundance present in granules at different periods were carried out using STAMP software (Parks and Beiko, 2010). In addition, to analysis the correlation between concentration of digestion product with microbial composition, Pearson correlation tests were performed with R. Raw reads were deposited in Sequence Read Archive (SRA) database (http://www.ncbi.nlm.nih.gov/sra) under the ID: PRJNA327299. Detailed sample IDs were listed in Table 2.

\section{Results}

\subsection{Reactor performance}

During the start up period, no significant gas production and $\mathrm{pH}$ changes was observed in the reactor. The $\mathrm{pH}$ value was maintained between 7 and 7.5. VFAs were 
accumulated and by the end of this period reached a value of approximately 3.95 \pm 0.19 $\mathrm{g} / \mathrm{L}$ in the reactor; no alcohol-like products were detected. When the reactor was fed at OLR of 3.97 \pm 0.19 gVS/(L-reactor.d), a significant increase of VFA concentration and decrease of $\mathrm{pH}$ in the reactor were observed (Fig. 1). The VFA concentration was stabilized at $9.85 \pm 0.09 \mathrm{~g} / \mathrm{L}$ and the $\mathrm{pH}$ values dropped to 5.7 after 21 days of operation (i.e. equal to 3 HRTs). The methane production was below the detection limit. Thus, in the second operation period, the influent feedstock was supplemented with bicarbonate in order to maintain the $\mathrm{pH}$ levels within the corresponding ones allowing methanogenesis. It was found that a significant production of methane was observed


the generation of alcohol-like product was eliminated and VFA concentration further increased to $15.7 \pm 0.04 \mathrm{~g} / \mathrm{L}$.

\subsection{Overall microbial diversity granular sludge}

In total, 1,277,236 paired sequences with average length of 250 bp were generated from triplicate samples at 4 different time points (G1, G2, G3 and G4). For the experiment, the OTU similarity threshold was set to 95\% corresponding to taxonomy at genus level (Yarza et al. 2014). The top 90\% of abundant OTUs were chosen for 16S rRNA amplicon sequencing analysis and will be further discussed. The triplicate samples were clustered closely in PCoA analysis (Fig. 2). Principal components 1 and 2 explained $74 \%$ and $14 \%$ of the total community variations, respectively. Granule samples were well separated at different experimental point. G2 samples were more close to G1 samples compared to G3. The phylogenetic tree in Fig. 3 showed the OTUs present in different granule samples. In total, 47 OTUs will be discussed including 31 OTUs characterized at genus level, 11 OTUs at family level, 4 OTUs at order level and 1 OTU at class level. The metabolic trophic role for each OTU was estimated according to previous literature on the same or higher taxonomic level of a specific microorganism.

\subsection{Taxonomical characterization in mesophilic granules}

The top $90 \%$ of microbial community from mesophilic granular (G1) consisted of bacteria (68.34\%) and archaea (21.83\%). A major group of the community (54.9\%) is composed by fermentative bacteria that preferably use proteins and sugars as substrate. This group also includes some OTUs such as members belonging to genus 
Streptococcus that can produce hydrolase that drives hydrolysis process (Martini et al. 2014). Within this part of community, genus T78, a member of family Anaerolinaceae, has high abundance (25.16\%), which is more than 4 times more than the second most abundant bacteria Syntrophobacter (6.2\%). The archaeal community contained only two genera identified as Methanobacterium (14.64\%) and Methanosaeta (7.19\%), which are hydrogenotrophic and acetoclastic methanogens respectively.

\subsection{Microbial changes of mesophilic granules after operation at thermophilic temperature}

The microbial community changed significantly after the temperature was increased to $55^{\circ} \mathrm{C}$, especially after operating the reactor continuously with OLR of $3.97 \pm 0.19$ gVS/(L-reactor.d). As shown in Fig. 4, in G2, 85.75\% of the initial OTUs remained in the granules, but 17 out of 47 OTUs underwent significantly changes $(p<0.05)$ in their relative abundances (Fig.5). Among the different trophic groups described above, methanogens had the greatest decrease $(p<0.05)$ in relative abundance (i.e. from $21.83 \%$ to $15.18 \%$ ). The relative abundance of members belonging to Methanosaeta decreased from $7.19 \%$ to $2.92 \%$, accounting for one of the major changes in the overall community. The result also showed significantly decrease of some bacteria such as Syntrophobacter from $6.20 \%$ to $2.12 \%$. After the first operation period (in G3), $59.53 \%$ of the initial microbial community was maintained in the granules. A significant decrease of methanogens and syntrophic fatty acid oxidizer abundances has been observed ( $\mathrm{p}<0.05$ ), while the newly emerged genera were all belonging to fermentative bacteria. The relative abundance of Methanobacterium was still $10.20 \%$ however relative abundance of Methanosaeta further decreased to $0.43 \%$. The most significant change among Bacteria was the increase of Ruminococcus. Ruminococcus species increased 7.3 folds $(\mathrm{p}<0.05)$ and reached relative abundance of $13.55 \%$. After the second experimental period, in G4, only 4 genera (22.82\% of relative abundance) of the initial microbial community remained in the granules. In particular, genus $T 78$, which is the most abundant genus in the mesophilic granules, remained a high relative abundance (19.54\%) through the whole experiment. The fermentative bacteria further increase in relative abundance but decreased in diversity. Some microbes, such as members in genus Ruminococcus increased in relative abundance in G3 but decreased in G4. However, members from genus Coprothermobacter and Tepidimicrobium were only 
enriched in G4 but not in G3. Members from Methanoculleus emerged by the end of this period, accounting for around $1 \%$ of total community.

\section{Discussion}

According to the taxonomical characterization of mesophilic granules used to initialize the reactor, the granule microbiota contained microbes covering all essential digestion steps for methane production. Among these microbes, genus T78 is a candidatus genus because of its unique 16S rRNA gene sequences compared with other genera belonging to the same taxon. This genus was previously found in anaerobic digestion and biogas systems, possibly metabolizing alcohols and carbohydrates via syntrophic interactions (Praveckova et al. 2016). Members from Genus T78 were taxonomically assigned to family Anaerolinaceae and predominated in the community throughout all three experiment periods. The cultured Anaerolinaceae members showed fermentative grow on carbohydrates and/or peptides and were found in several studies both in the outer layer and inside of sludge granules (Yamada and Sekiguchi 2009). They commonly have multicellular filamentous morphology, therefore Anaerolineae are considered important bacteria for granulation of sludge and maintenance of granular structure (Yamada et al. 2005; Satoh et al. 2007). Syntrophobacter species, the second most abundant OTU, have been reported multiple times to degrade propionate to acetate with syntrophic hydrogen removal methanogens (Schink 1997; Liu et al. 1999) and use the end product of fermentative bacteria to produce acetate, $\mathrm{H}_{2}$ and $\mathrm{CO}_{2}$ (Sieber et al. 2012). The predictive functional profile of this genus showed extremely high number of genes belonging to second carbon oxidation (2-oxoglutarate to oxaloacetate), which validates its role as syntrophic oxidizer (Supplementary Table S1). These acetogenic bacteria were found in low abundance probably because only a small part of the fermented products were further oxidized to acetate and hydrogen inside the granules. It can be highlighted that the established community of the original mesophilic granules had a balanced composition between the fermentative bacteria and methanogens. Consequently, this microbial balance assisted the efficient degradation of the substrate to methane, as confirmed by the low concentration of intermediate metabolic compounds (VFAs) during the operation in wastewater plant. The archaeal community had a lower diversity which contained only two genera identified as hydrogenotrophic and acetoclastic methanogens accordingly. This observation was in accordance with the 
funnel shape community previously identified in anaerobic digestion system (Campanaro et al. 2016).

During the start up period, the $\mathrm{pH}$ value was maintained between 7 and 7.5 because the reactor was initially filled with BA medium, which included bicarbonate as $\mathrm{pH}$ buffer. VFAs were accumulated and by the end of this period indicating that the organic matter in potato juice was degraded through hydrolysis and acidogenesis. However, the lack of gas production implied that methanogenesis was not established. The microbial community composition changed slightly during this period, as the majority of genera present in G1 remained in G2. The consistency of the community could be explained by the fact that during the start up period, only $40 \mathrm{~mL}$ of potato juice was used as feeding and no significantly wash-out occurred because of the long retention time and short time period. Moreover, the microbes were firmly immobilised in the granule and therefore were not easily washed out. The decrease in abundance of Methanosaeta is one of the major changes in the overall community, which was consistent with the findings of previous studies (Khemkhao et al. 2012). This result confirmed that the mesophilic Methanosaeta cannot actively perform methanogenesis at thermophilic conditions and markedly decrease in relative abundance. The significant decrease of Syntrophobacter was in accordance with the fact that VFA was accumulated during this period. This result indicated that Syntrophobacter members did not preferably grow at thermophilic condition. Moreover, it is well known that during fatty acid degradation there is a significant role of syntrophic microbial interactions in order to accomplish quinonemediated interspecies electron transfer (Kougias et al. 2016). These interactions could be served by syntrophic association between acetogenic bacteria and methanogenic archaea or sulphate-reducing bacteria (Wang et al. 2015). Therefore, the low activity of methanogens in the present study probably resulted in high hydrogen partial pressure, which limited the chances of syntrophic acetogens such as Syntrophobacter to oxidise volatile fatty acids, due to unfavourable thermodynamics.

When a OLR of $3.97 \pm 0.19 \mathrm{gVS} /(\mathrm{L}-$-reactor.d) applied, the result showed a significant increase of VFA concentration and decrease of $\mathrm{pH}$, which indicated that these mesophilic granules could not perform in terms of methane production under thermophilic conditions $\left(55^{\circ} \mathrm{C}\right)$ without applying a long-term acclimatization period or other deliberate actions such as $\mathrm{pH}$ control or bioaugmentation. Furthermore, because a 
feasible biomethanation process could occur at $\mathrm{pH}$ range between 6.0 and 8.5 (Bassani et al. 2015), the low $\mathrm{pH}$ environment further inhibited the methanogenesis and promoted the fermentation of alcohol-like product. It was observed that the hydrolytic and fermentative microbes can quickly be integrated in the granules, while the thermophilic methanogens and syntrophic fatty acid oxidizer grew slowly. Ruminococcus species which became the second most abundant OTU, was reported as hydrolytic and fermentative bacteria (Azman et al. 2015) and commonly found in biohydrogen production system where $\mathrm{pH}$ was around 5 (Ntaikou et al. 2008). The radical increase of Ruminococcus species suggested that members from this genus especially favoured this environment possibly due to the high tolerance to low $\mathrm{pH}$ environment. The results of Pearson tests revealed a significant positive correlation between the relative abundance of Ruminococcus and the alcohol concentration $(p=0.03)$. The representative sequence of this OTU was compared with NCBI database using BLASTN and the closest match was Ruminococcus bromii (91\% identity), which contained multiple genes for production of short-chain alcohol according to its draft genome deposited in NCBI data base (sample ID: SAMEA3138353). Moreover, the predictive functional profile of this genus showed that Ruminococcus has a higher gene content related to glycolysis as well as citrate cycle pathways (Supplementary Table S1). As a consequence, these features could attribute to its capability to anaerobically degrade organic compounds and produce alcohol. The lack of methane production indicated that the methanogens were not actively producing methane at thermophilic conditions, although the relative abundance of Methanobacterium was still high and equal to $10.20 \%$. This phenomenon could be explained by the fact that the representative sequence of this OTU was found 99\% similar to Methanobacterium beijingense that grows at $25-50^{\circ} \mathrm{C}$ with optimal at $37^{\circ} \mathrm{C}$ (Ma et al., 2005), and therefore the applied operational temperature might inhibited its activity. The relative abundance of Methanosaeta further decreased to $0.43 \%$ which could be explained by a more efficient washout effect with the shorter HRT applied during this period. However, the present study showed that the structure of the granules could be maintained when even Methanosaeta decrease dramatically. The maintenance of the granules without Methanosaeta species was conflicting with few studies reporting Methanosaeta as the key organism in anaerobic sludge granulation (Pol et al. 2004). 
Previous study reported that potato processing starch wastewater was of low alkalinity and $\mathrm{pH}$ was a sensitive alert of process failure (Yu et al. 2016). Therefore, to obviate the $\mathrm{pH}$ impact on the evolvement of methanogenic microbial community in the granules, additional sodium bicarbonate was supplemented in the substrate to maintain the $\mathrm{pH}$ value higher than 6.5. The increased of $\mathrm{pH}$ eliminated the production of alcohols and promoted the production of VFAs and methane. The microbial community composition shifted to new state where the fermentative bacteria were replaced with microbes that are more adaptable to relatively high $\mathrm{pH}$ environment. Members that found significantly increased in relative abundance during this period (i.e. members from genus S1) were previously reported to present at anaerobic digestion system with other configuration (Frank et al. 2016), suggesting that those members preferably grow at $\mathrm{pH}$ higher than 6.5, which is the typical $\mathrm{pH}$ for anaerobic digestion. Members from genus Coprothermobacter and Tepidimicrobium were both reported as thermophilic fermentative bacteria preferring pH 7-8 (Rainey and Stackebrandt 1993; Slobodkin et al. 2006). Furthermore, the hydrogenotrophic methanogen genus, Methanoculleus that was not identified in the previous periods emerged in the community, being most probable the responsible methanogen for the production of methane during this period. The methane yield in this experiment was low compared with previous yields achieved in mesophilic condition (Fang et al. 2011), because the process was inhibited due to unbalanced microbial composition. In the adapted granules, the relative abundance of syntrophic fatty acid oxidizers and methanogens were found significantly lower ( $p$ $<0.05)$ compared to their abundance population in the initial community. This result is consistent with the low methane yields and the accumulation of VFAs in the reactor. However, the presence of methanogenesis proved that among members in mesophilic granules, there are microbes that can survive at thermophilic conditions. These results indicated that mesophilic granular could be used as a potential seed for start-up of thermophilic UASB reactors feeding with potato juice. However it should be stressed out that the methane yield was extremely low and the process severely inhibited.

To summarize, this study demonstrated that the start-up of a thermophilic UASB reactor with mesophilic granules requires granular microbiota shifts from mesophiles to thermophiles. It was shown that members of Anaerolinaceae family contributed in the maintenance of granular structure. Moreover, it was demonstrated that shortly after the 
temperature shift the microbial community changed into a new consortium. Thermophilic hydrolytic and fermentative bacteria were the first to evolve in the granular microbiota, leading to VFA accumulation and concomitant $\mathrm{pH}$ drop, which in turn resulted in no detectable methane production. The inhibition of methanogenesis was reversible as soon as the $\mathrm{pH}$ was deliberately maintained at values higher than 6.5.

\section{Acknowledgement}

We thank Hector Garcia and Hector Diaz for technical assistance. This work was supported by the Danish Council for Strategic Research under the project "SYMBIO Integration of biomass and wind power for biogas enhancement and upgrading via hydrogen assisted anaerobic digestion”, contract 12-132654. Illumina sequencing was performed at the Ramaciotti Centre for Genomics (Sydney, Australia).

\section{Compliance with ethical standards}

\section{Conflict of interest}

The authors declare that they have no conflict of interest.

\section{Ethical approval}

This article does not contain any studies with human participants or animals performed by any of the authors.

\section{References}

Angelidaki I, Ellegaard L, Ahring BK (1992) Compact automated displacement gas metering system for measurement of low gas rates from laboratory fermentors. Biotechnol Bioeng 39:351-353.

Angelidaki I, Sanders W (2004) Assessment of the anaerobic biodegradability of macropollutants. Re/Views Environ Sci \{\&\} Bio/Technology 3:117-129.

APHA (2005) Standard Methods for the Examination of Water and Wastewater. American Public Health Association.

Azman S, Khadem AF, Van Lier JB, Zeeman G, Plugge CM (2015) Presence and role of anaerobic hydrolytic microbes in conversion of lignocellulosic biomass for biogas production. Crit Rev Environ Sci Technol 45:2523-2564. 
Bassani I, Kougias PG, Treu L, Angelidaki I (2015) Biogas upgrading via hydrogenotrophic methanogenesis in two-stage continuous stirred tank reactors at mesophilic and thermophilic conditions. Environ Sci Technol 49:12585-12593.

Bouallagui H, Haouari O, Touhami Y, Ben Cheikh R, Marouani L, Hamdi M (2004) Effect of temperature on the performance of an anaerobic tubular reactor treating fruit and vegetable waste. Process Biochem 39:2143-2148.

Boušková A, Dohanyos M, Schmidt JE, Angelidaki I (2005) Strategies for changing temperature from mesophilic to thermophilic conditions in anaerobic CSTR reactors treating sewage sludge. Water Res 39:1481-1488.

Bzducha-Wróbel A, Błażejak S, Molenda M, Reczek L (2015) Biosynthesis of $\beta$ (1, $3) /(1,6)$-glucans of cell wall of the yeast Candidautilis ATCC 9950 strains in the culture media supplemented with deproteinated potato juice water and glycerol. Eur Food Res Technol 240:1023-1034.

Campanaro S, Treu L, Kougias PG, Francisci D, Valle G, Angelidaki I (2016) Metagenomic analysis and functional characterization of the biogas microbiome using high throughput shotgun sequencing and a novel binning strategy. Biotechnol Biofuels 9:1.

Carrillo-Reyes J, Celis LB, Alatriste-Mondragón F, Razo-Flores E (2014) Decreasing methane production in hydrogenogenic UASB reactors fed with cheese whey. Biomass and Bioenergy 63:101-108.

Castrillon L, Vázquez I, Maranon E, Sastre H (2002) Anaerobic thermophilic treatment of cattle manure in UASB reactors. Waste Manag Res 20:350-356.

De Francisci D, Kougias PG, Treu L, Campanaro S, Angelidaki I (2015) Microbial diversity and dynamicity of biogas reactors due to radical changes of feedstock composition. Bioresour Technol 176:56-64.

Fang C, Boe K, Angelidaki I (2011) Biogas production from potato-juice, a by-product from potato-starch processing, in upflow anaerobic sludge blanket (UASB) and expanded granular sludge bed (EGSB) reactors. Bioresour Technol 102:57345741.

Fang H, Lau I (1996) Startup of thermophilic (55UC) UASB reactors using different 
mesophilic seed sludges. Water Sci Technol 34:445-452.

Frank JA, Pan Y, Tooming-Klunderud A, Eijsink VGH, McHardy AC, Nederbragt AJ, Pope PB (2016) Improved metagenome assemblies and taxonomic binning using long-read circular consensus sequence data. Sci. Rep.6:25373

Khemkhao M, Nuntakumjorn B, Techkarnjanaruk S, Phalakornkule C (2012) UASB performance and microbial adaptation during a transition from mesophilic to thermophilic treatment of palm oil mill effluent. J Environ Manage 103:74-82.

Kougias PG, Boe K, Einarsdottir ES, Angelidaki I (2015) Counteracting foaming caused by lipids or proteins in biogas reactors using rapeseed oil or oleic acid as antifoaming agents. Water Res 79:119-127.

Kougias PG, De Francisci D, Treu L, Campanaro S, Angelidaki I (2014) Microbial analysis in biogas reactors suffering by foaming incidents. Bioresour Technol 167:24-32.

Kougias PG, Treu L, Campanaro S, Zhu X, Angelidaki I (2016) Dynamic functional characterization and phylogenetic changes due to Long Chain Fatty Acids pulses in biogas reactors. Sci. Rep 6:28810

Liu Y, Balkwill DL, Aldrich HC, Drake GR, Boone DR (1999) Characterization of the anaerobic propionate-degrading syntrophs Smithella propionica gen. nov., sp. nov. and Syntrophobacter wolinii. Int J Syst Evol Microbiol 49:545-556.

Lu X, Zhen G, Estrada AL, Chen M, Ni J, Hojo T, Kubota K, Li Y-Y (2015) Operation performance and granule characterization of upflow anaerobic sludge blanket (UASB) reactor treating wastewater with starch as the sole carbon source. Bioresour Technol 180:264-73.

Luo G, De Francisci D, Kougias PG, Laura T, Zhu X, Angelidaki I (2015) New steadystate microbial community compositions and process performances in biogas reactors induced by temperature disturbances. Biotechnol Biofuels 8:3.

Mao C, Feng Y, Wang X, Ren G (2015) Review on research achievements of biogas from anaerobic digestion. Renew Sustain Energy Rev 45:540-555.

Martini M, Marcone C, Lee IM, Firrao G (2014) The Prokarytoes-Firmicutes and 
Tenericutes, 4th Editio. Springer Heidelberg New York Dordrecht London

Ntaikou I, Gavala HN, Kornaros M, Lyberatos G (2008) Hydrogen production from sugars and sweet sorghum biomass using Ruminococcus albus. Int J Hydrogen Energy 33:1153-1163.

Parawira W, Murto M, Read JS, Mattiasson B (2007) A study of two-stage anaerobic digestion of solid potato waste using reactors under mesophilic and thermophilic conditions. Environ Technol 28:1205-1216.

Pol LWH, de Castro Lopes SI, Lettinga G, Lens PNL (2004) Anaerobic sludge granulation. Water Res 38:1376-1389.

Praveckova M, Brennerova M V, Holliger C, De Alencastro F, Rossi P (2016) Indirect evidence link PCB dehalogenation with Geobacteraceae in anaerobic sedimentfree microcosms. Front Microbiol 7:933.

Rainey FA, Stackebrandt E (1993) Transfer of the Type Species of the Genus Thermobacteroides to the Genus Thermoanaerobacter as Thermoanaerobacter acetoethylicus (Ben-Bassat and Zeikus 1981) comb. nov., Description of Coprothermobacter gen. nov., and Reclassification of Thermobacteroides. Int J Syst Evol Microbiol 43:857-859.

Satoh H, Miura Y, Tsushima I, Okabe S (2007) Layered structure of bacterial and archaeal communities and their in situ activities in anaerobic granules. Appl Environ Microbiol 73:7300-7307.

Schink B (1997) Energetics of syntrophic cooperation in methanogenic degradation. Microbiol Mol Biol Rev 61:262-280.

Sieber JR, McInerney MJ, Gunsalus RP (2012) Genomic insights into syntrophy: the paradigm for anaerobic metabolic cooperation. Annu Rev Microbiol 66:429-452.

Slobodkin AI, Tourova TP, Kostrikina NA, Lysenko AM, German KE, BonchOsmolovskaya EA, Birkeland N-K (2006) Tepidimicrobium ferriphilum gen. nov., sp. nov., a novel moderately thermophilic, Fe (III)-reducing bacterium of the order Clostridiales. Int J Syst Evol Microbiol 56:369-372.

Syutsubo K, Harada H, Ohashi A, Suzuki H (1997) An effective start-up of 
thermophilic uasb reactor by seeding mesophilically-grown granular sludge. Water Sci Technol 36:391-398.

Vlyssides A, Barampouti EM, Mai S (2008) Granulation mechanism of a UASB reactor supplemented with iron. Anaerobe 14:275-9.

Wang H, Fotidis IA, Angelidaki I (2015) Ammonia effect on hydrogenotrophic methanogens and syntrophic acetate-oxidizing bacteria. FEMS Microbiol Ecol 91:11.

Yamada T, Sekiguchi Y (2009) Cultivation of uncultured Chloroflexi subphyla: significance and ecophysiology of formerly uncultured Chloroflexi'subphylum I’with natural and biotechnological relevance. Microbes Environ 24:205-216.

Yamada T, Sekiguchi Y, Imachi H, Kamagata Y, Ohashi A, Harada H (2005) Diversity, localization, and physiological properties of filamentous microbes belonging to Chloroflexi subphylum I in mesophilic and thermophilic methanogenic sludge granules. Appl Environ Microbiol 71:7493-7503.

Yarza P, Yilmaz P, Pruesse E, Glöckner FO, Ludwig W, Schleifer K-H, Whitman WB, Euzéby J, Amann R, Rosselló-Móra R (2014) Uniting the classification of cultured and uncultured bacteria and archaea using 16S rRNA gene sequences. Nat Rev Microbiol 12:635-645.

Yu D, Liu J, Sui Q, Wei Y (2016) Biogas-pH automation control strategy for optimizing organic loading rate of anaerobic membrane bioreactor treating high COD wastewater. Bioresour Technol 203:62-70.

Zhang Y, Wang X, Hu M, Li P (2015) Effect of hydraulic retention time (HRT) on the biodegradation of trichloroethylene wastewater and anaerobic bacterial community in the UASB reactor. Appl Microbiol Biotechnol 99:1977-1987. 


\section{Tables}

Table 1 Characteristics of the raw potato juice

\begin{tabular}{lll}
\hline Characteristics & Mean \pm S.D & Unit \\
\hline Total Solids (TS) & $230.25 \pm 1.40$ & $\mathrm{~g} / \mathrm{L}$ \\
Volatile Solids (VS) & $163.98 \pm 2.78$ & $\mathrm{~g} / \mathrm{L}$ \\
Ammonia nitrogen & $1.83 \pm 0.04$ & $\mathrm{~N}(\mathrm{~g} / \mathrm{L})$ \\
Total Kjeldahl Nitrogen (TKN) & $9.35 \pm 0.12$ & $\mathrm{~N}(\mathrm{~g} / \mathrm{L})$ \\
Chemical Oxygen Demand (COD) & $191.50 \pm 1.34$ & $\mathrm{~g} / \mathrm{L}$ \\
pH & 5.23 & - \\
\hline
\end{tabular}


Table 2. Summary presenting the sequencing results

SAMPLE NAME

Mesophilic methanogenic granules (G1)

Granules during temperature adaptation (G2)

Granules after temperature adaptation (G3)

Granules operating with pH control (G4)
SRA ACCESION NUMBER

SAMN05328136

SAMN05328135

SAMN05328134

SAMN05328133 


\section{Figure captions}

Fig. 1 The methane yield, pH values and VFA concentration for operation periods.

Fig. 2 Beta diversity with Bray-Curtis dissimilarity G1-1, 2, 3 are the triplicate mesophilic granule samples. G2-1, 2, 3 are triplicate granule samples after start up period. G3-1, 2 are replicate granule samples after operation 1. G4-1, 2, 3 are triplicate granule samples after operation 2 .

Fig. 3 Phylogenetic tree for microbial community in G1, G2, G3 and G4.

Fig. 4 Relative abundance of OTUs in the community. The redline indicate the changing of initial community.

Fig. 5 OTUs that changed significantly ( $<$ 0.05) compared to G1. a) OTUs in G2 that changed significantly b) OTUs in G3 that changed significantly c) OTUs in G3 that changed significantly. 


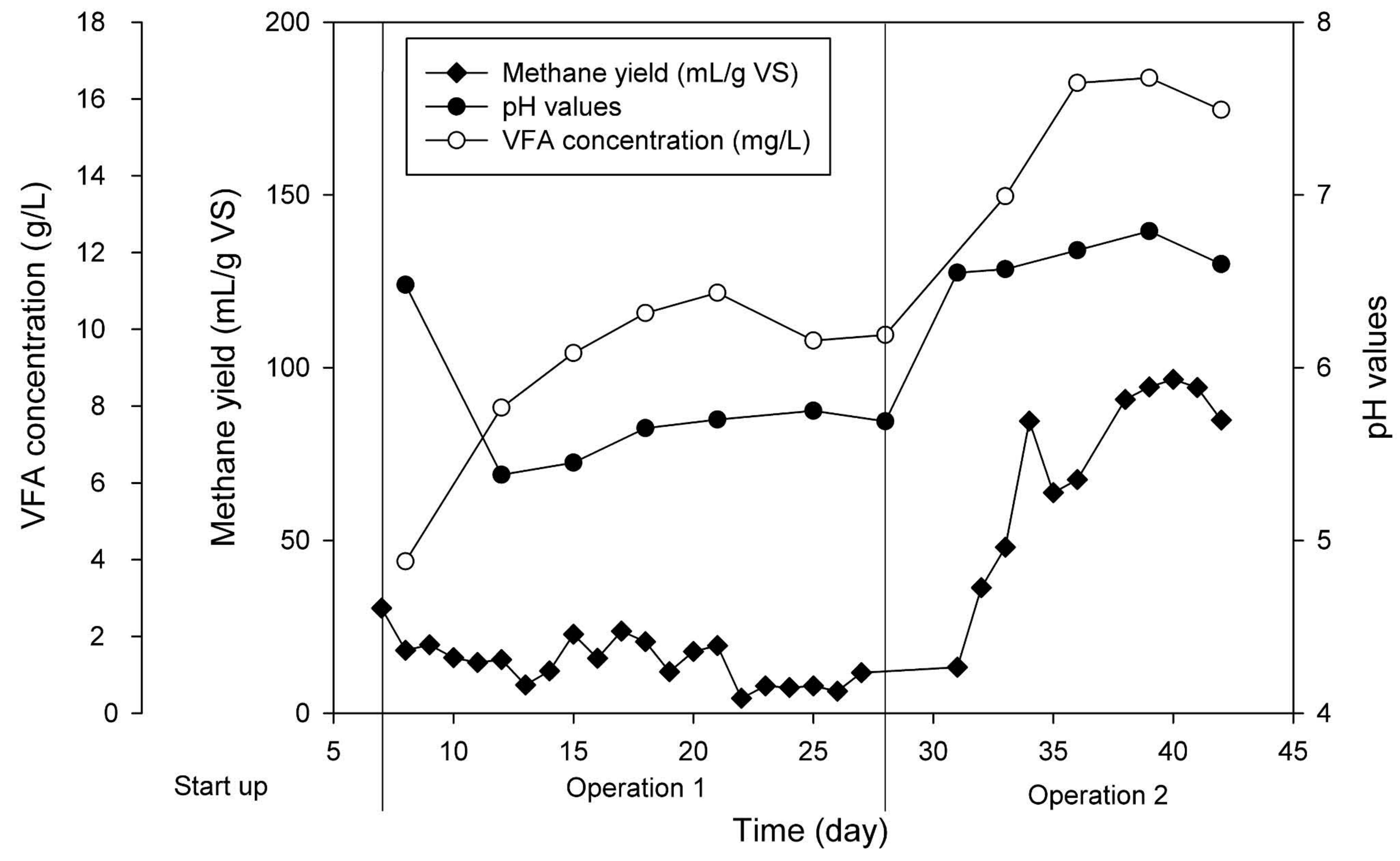




\section{PCoA_Bray-Curtis}

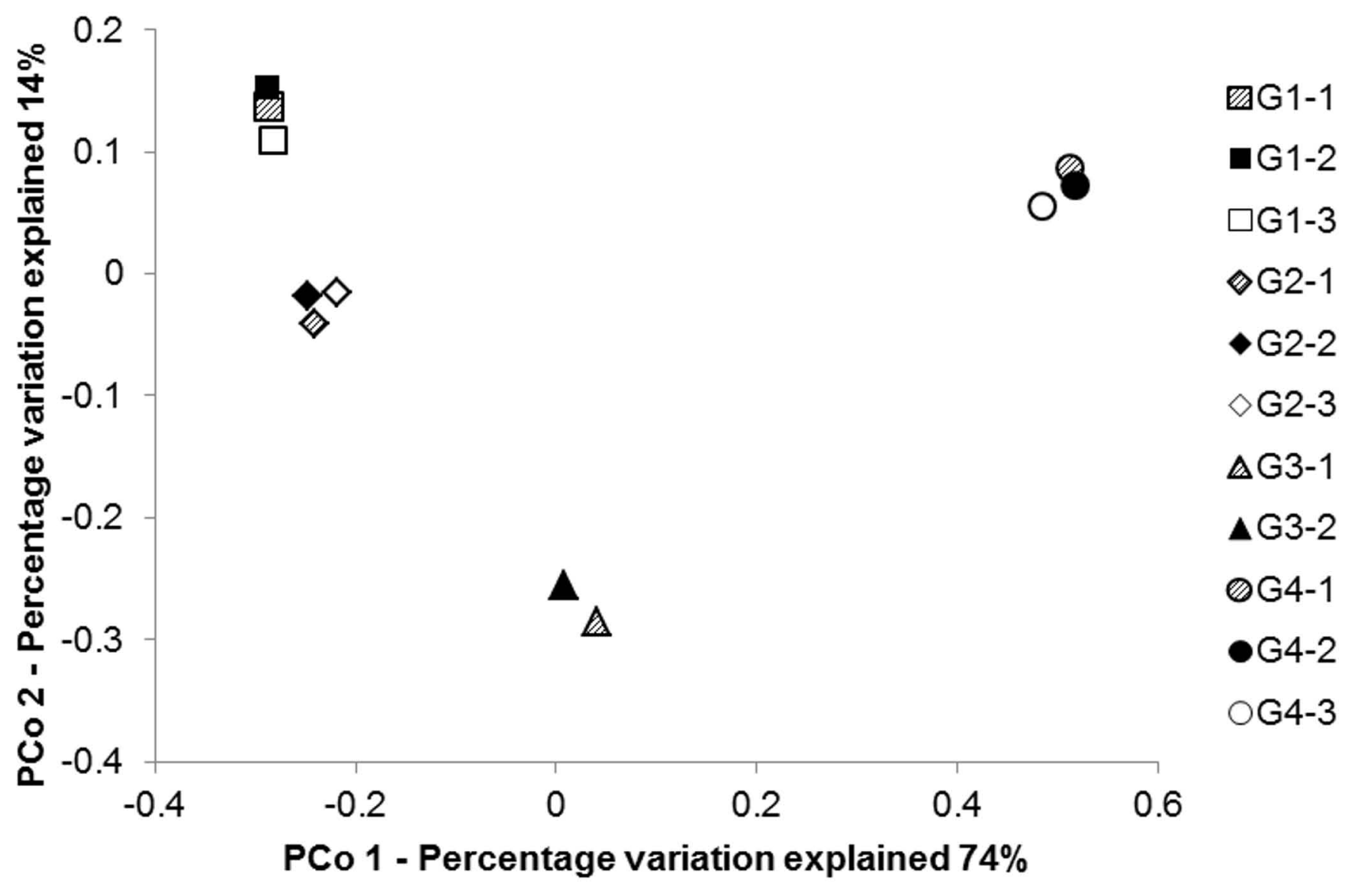




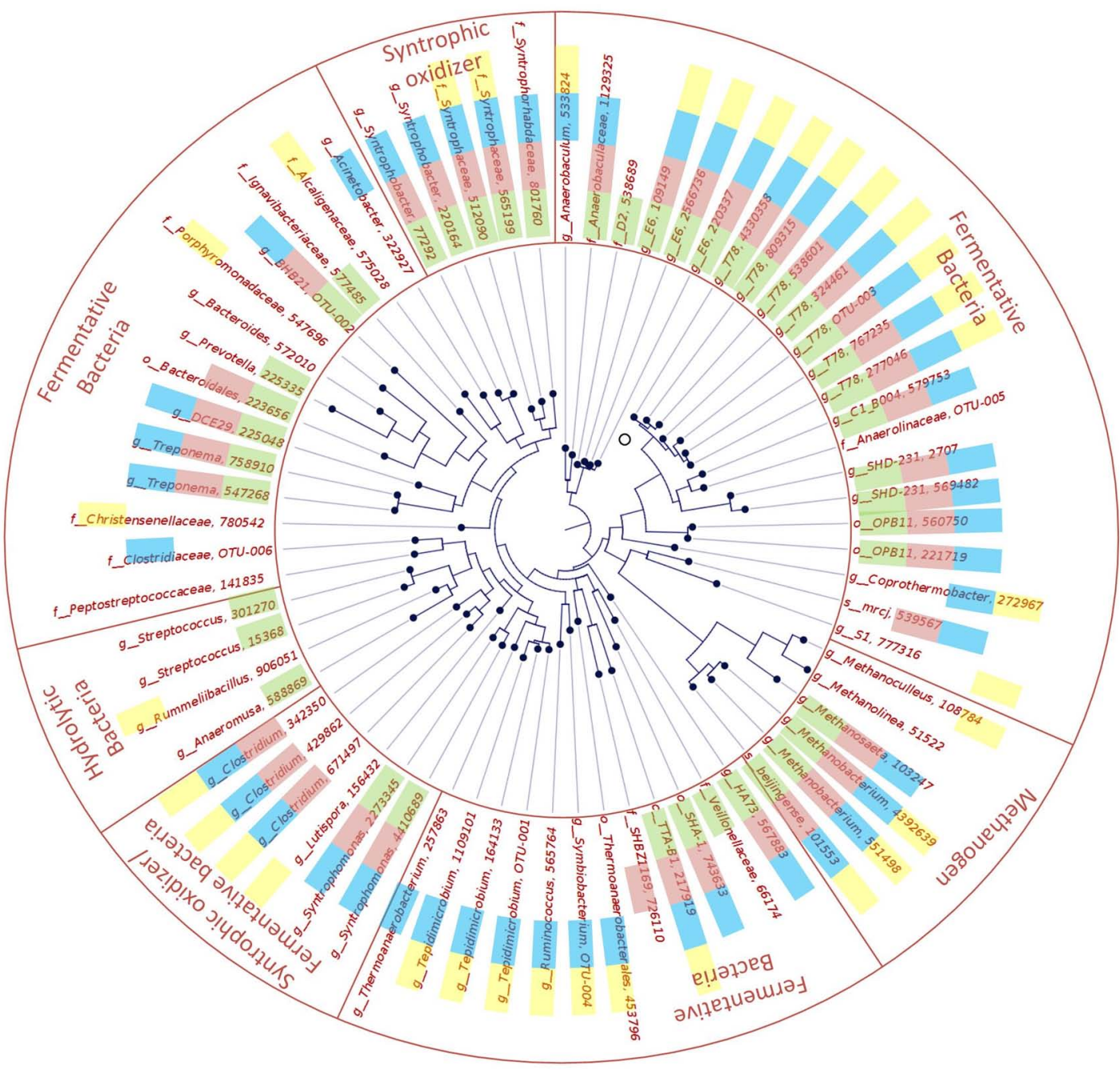




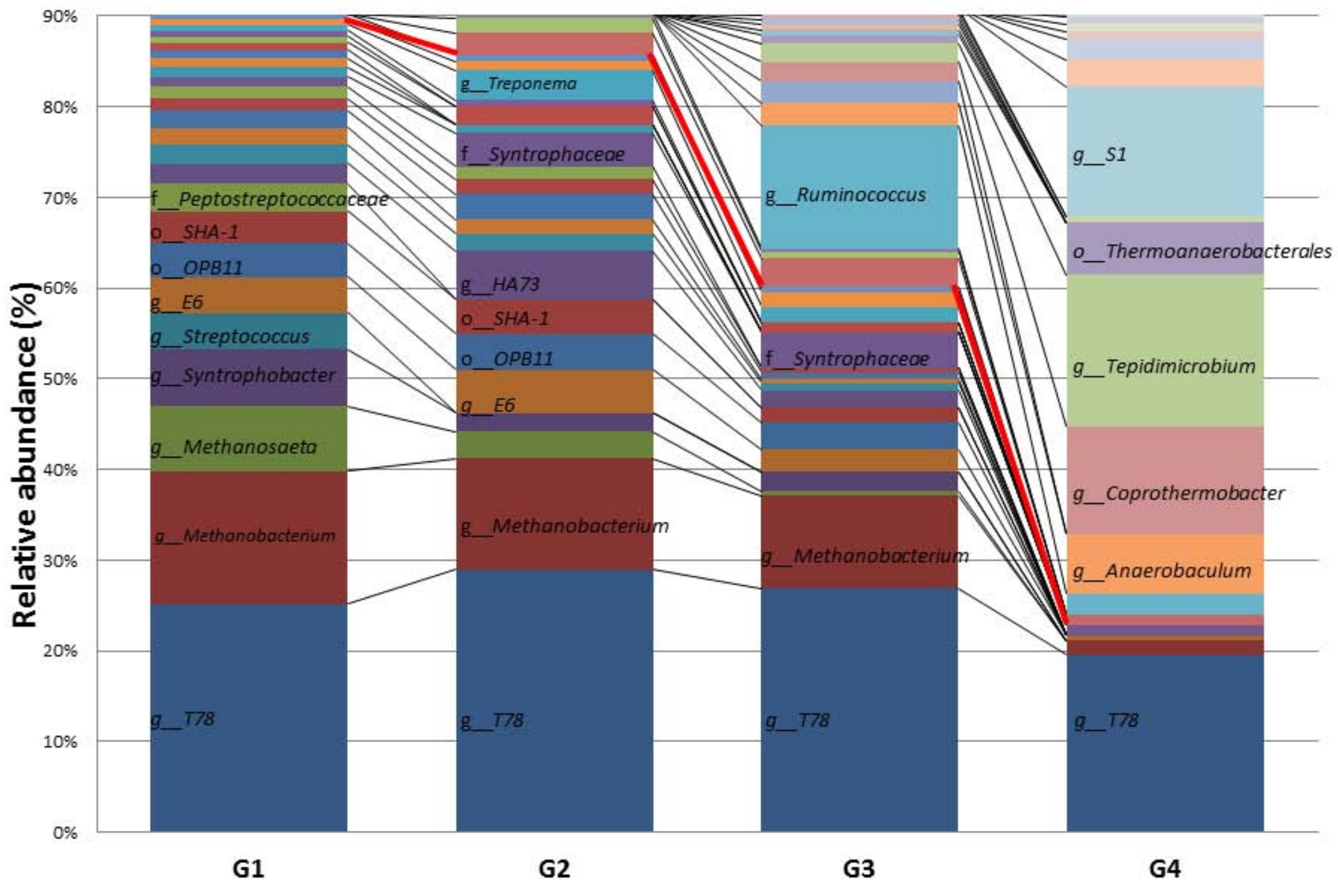




\section{$95 \%$ confidence intervals}

g_Methanosaeta

$f$ _Syntrophaceae 2

8_Syntrophomonas 3

$f$ Ignavibacteriaceae

c_ $\pi$ TA-B1 3

g_Syntrophobacter

g_Lutispora i

g_Treponema b s_ 778

9_Clostridium b

3. Streptococcus

f_Christensenellaceae |

o_thermoanaerobacterales is

$f$ Porphyromonadaceae $P$ g_SHD-231 g_HA73

g_Prevotella "

a)

0.0

g_Syntrophomonas

S_Kosmotoga 3

g_ Methanosaeta

g_Anaerobaculum

g_Coprothermobacter $\leftrightharpoons$

g_Thermoanaerobacterium g_Treponema is

f_Syntrophaceae

S_Tepidimicrobium

$f \_S y n t r o p h o r h a b d a c e a e ~ \Xi$

o_Bacteroidales $P$

$f \_$gnavibacteriaceae $P$

g_Symbiobacterium b

o_Thermoanaerobacterales b

$f \_$Anaerobaculaceae 5

g_Ruminococcus

f_Christensenellaceae |

g_Syntrophobacter $\equiv$

S_E6 E

g. Rummeliibacillus |

s_Caloramator b

f_Porphyromonadaceae !

8_Lutispora

o_SHA-1 E

g_Clostridium

S_DCE29 开

$f \_D 2$ P

o_OPB11

$f \_$Alcaligenaceae

g_Streptococcus

$f$ _Peptostreptococcaceae

g_Prevotella P

g_s1 1

b)

$\begin{array}{ll}0.0 & 14.6 \\ \text { Mean proportion }(\%)\end{array}$
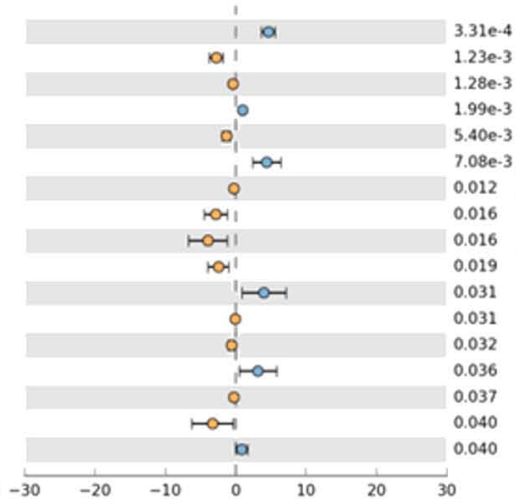

$3.53 \mathrm{e}-4$

$5.12 \mathrm{e}-4$

$5.56 \mathrm{e}-4$

8.30e-4

$8.56 \mathrm{e}-4$

$1.14 \mathrm{e} \cdot 3$

$1.59 \mathrm{e}-3$

$1.68 \mathrm{e}-3$

$1.76 \mathrm{e} \cdot 3$

$1.89 \mathrm{e} \cdot 3$

$1.93 \mathrm{e}-3$

$1.96 \mathrm{e} \cdot 3$

$1.97 \mathrm{e}-3$

$2.10 \mathrm{e} \cdot 3$

$2.50 \mathrm{e}-3 \mathrm{~g}$

$2.65 \mathrm{e}-3$

$4.66 \mathrm{e}-3$

$6.13 \mathrm{e}-3$

$6.27 \mathrm{e}-3$

$6.99 \mathrm{e} \cdot 3$

0.010

0.010

0.012

0.013

0.017

0.022

0.023

0.02

0.027

0.038

0.047

0.049
Difference in mean proportions (\%)

O_OPB11

g_Syntrophomonas $P$

o_Bacteroidales $P$

g Methanosaeta

g_SHD-231 P

$f \_$Syntrophorhabdaceae $P$

$f$ Ignavibacteriaceae $P$ g_S1

g_Thermoanaerobacterium b

o_SHA-1

o_Thermoanaerobacterales

g_Syntrophobacter $f \_D 2 \mathrm{P}$

g_-Methanobacterium

g_Kosmotoga g_HA73 $\mathrm{F}$

f_Christensenellaceae g_DCE29 Р

S_Tepidimicrobium g_ Lutispora

S_Anaerobaculum g_C1_BOO4 P

g Symbiobacterium

g_Coprothermobacter

g_Caloramator

g_ Streptococcus

f_SHBZ1169 P

g_Treponema $\mathbf{P}$

$f$ Peptostreptococcaceae

g_Comamonas I

g_Clostridium 10

g_Prevotella $P$

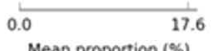

Mean proportion (\%)

c)



\author{
30
}

\section{$95 \%$ confidence intervals}

